\title{
Progress AND Challenges in THE IMPLEMENTATION OF ELECTRONIC MEDICAL RECORdS IN SAUdi ARABIA: A SYSTEMATIC REVIEW
}

\author{
Rihab Hasanain ${ }^{1}$, Kirsten Vallmuur ${ }^{2}$ and Michele Clark ${ }^{3}$ \\ ${ }^{1}$ School of Public Health and Social Work, Queensland University of Technology, \\ Brisbane, Australia \\ ${ }^{2}$ School of Psychology and Counselling, Queensland University of Technology, \\ Brisbane, Australia \\ ${ }^{3}$ School of Clinical Sciences, Queensland University of Technology, Brisbane, Australia
}

\begin{abstract}
Electronic Medical Record (Emr) Systems Are Being Implemented Increasingly Worldwide. Saudi Arabia Is One Of Developing Countries That Commenced Implementing Such Systems In 1988. Whilst Emr Uptake Has Been Low In Saudi Arabia Until Now, A Number Of Hospitals Have Implemented Emr Systems Successfully. This Paper Analyses Available Studies $(N=28)$ In The Literature Regarding Emr Implantation In Saudi Arabia To Identify The Progress Of Emr Implementation To Date And To Identify The Facilitators And Barriers To Implementation.
\end{abstract}

\section{KEYWORDS}

Electronic Medical Records; Health Information Systems; Saudi Arabia.

\section{INTRODUCTION}

As populations grow and age additional demands are placed on healthcare facilities and providers. Globally, Health Information Systems (HIS) and technologies are being used increasingly and are seen as a way to increase hospital efficiency and the quality of patient care (1). HIS enable healthcare providers to document relevant patient information and provide efficient and improved healthcare services(2). Healthcare organizations achieve these outcomes through the use of HIS such as Electronic Medical Records (EMR), Computer Based Patient Records (CBPR), Automated Health Records (AHR) and Electronic Patient Records (EPR) all of which enable patient information to be recorded electronically. For the purposes of this study the term EMR includes any of the aforementioned systems.

The uptake of EMR systems throughout the world has occurred at different rates, with developing countries tending to lag behind more developed nations (3). Globally, the idea of recording patient health record electronically commenced during the 1960s (4). EMR systems were introduced in 1988 in Saudi Arabia, to improve the Saudi healthcare system and its services and to assist in better meeting the demands placed on health organizations (4). The Saudi Ministry of Health $(\mathrm{MOH})$ made the introduction of EMRs as one of its priorities and it plans to implement EMR nationwide (4). The Saudi MOH expected a number of improvements to the healthcare 
system from EMRs including reduced patient waiting times, improved flow of patient information and a reduction in errors and the duplication of records (5).

There are several successful examples of EMR implementation in Saudi Arabia and some hospitals have even earned excellence awards for their EMR implementation achievements(4). However, it has also been noted in the literature that systems such as EMRs are uncommon within Saudi hospitals(6). A number of challenges to EMRs implementation have been identified as key factors hampering EMR uptake (6). The purpose of this article is to review the literature in order to identify EMR implementation progress to date in Saudi Arabia and to also identify the factors which have assisted and hindered EMR implementation in this context.

\subsection{EMRs}

Numerous authors have defined the term EMR in the literature. While there is no generally agreed definition, there are a number of recurring concepts which have been presented by several organizations (7) (8) (9). The National Alliance for Health Information Technology (NAHIT) has defined EMR as 'an electronic record of health-related information on an individual that can be created, gathered, managed, and consulted by authorized clinicians and staff within one healthcare organization'. In other words, EMR is a computerized record that maintains patients' health related data, which is available to be used and accessed, only by authorized personnel, in order to deliver health care services within the health organization(7) .

\subsection{The Saudi Healthcare System}

Saudi Arabia is one of the developing countries that is trying to adjust to worldwide developments and technologies in order to improve the health of its citizens (5). In Saudi Arabia there are 244 hospitals (4). Approximately $60 \%$ of these are public hospitals which fall under the jurisdiction of the Ministry of Health, while the remaining are provided by either the private sector, University hospitals or other governmental departments such as the Ministry of Defense and Aviation (10).

The Saudi MOH public hospitals provide healthcare services at primary, secondary and tertiary levels to all citizens free of charge (11). The Saudi MOH budget in 2007 was 5.6\% of the total governmental budget, with $\$ 277$ U.S. dollars expenditure per capita per year.(12).

In the 1980s, an integrated EHR system was first developed, that was capable of sharing health information across different organizations (4). Further roll-out of EMR systems in Saudi MOH hospitals has been noted as progressing slowly (13). The literature reveals that there are a number of reasons leading to the poor uptake of EMRs in Saudi Arabia (4). It has also been noted that different initiatives aimed at EMR implementation and improvements were neither coordinated nor cooperative (14). Although progress to date has been impeded, the $\mathrm{MOH}$ has identified the importance of adopting an information system within hospitals that will ultimately link all hospitals within in Saudi Arabia (15) (4). Thus, this article focuses on reviewing progress to date in EMR implementation in Saudi Arabia. Additionally, it reviews the reasons leading to the poor uptake of EMRs implementations in Saudi Arabia, which have been considered as barriers to implementation in Saudi hospitals.

\section{OBJECTIVES}

The objectives of this study are to undertake a systematic review of the literature in order to examine the current status and availability of EMRs in Saudi Arabia, and identify the facilitators 
and barriers impacting EMR implementation. An additional objective was to explore the initiatives undertaken by the $\mathrm{MOH}$ for EMR implementation and to outline its achievements to date in the adoption of EMRs.

\section{MethodS}

An extensive search of research in the field of EMRs in Saudi Arabia was conducted using health databases and related articles were extracted. Databases searched for this study included Emerald, ProQuest, PubMed, SAGE Journals, Informit, Health Reference Centre and Google Scholar. Relevant reports in English language were extracted and a manual search of the references lists of review and other articles was undertaken. The search targeted studies between the years 2003 until 2013, as no studies were found prior to the year 2003. The main search terms included Electronic Medical Records and Electronic Health Records, associated with the text 'Kingdom of Saudi Arabia'. A further search was conducted using other relevant keywords, in order to expand the search strategy follows:

Saudi AND Electronic Medical Record* OR Electronic Health Record*, Saudi AND

EMR OR EHR, Saudi AND Health Information System*, Saudi AND Computer Based

Patient Record OR Automated Health Record*, Saudi AND Electronic Patient Record*

OR EPR, Saudi AND AHR OR CBPR, Health Informatics AND Saudi.

\subsection{Information Source}

The collected scholarly information included articles, theses, conference papers and presentation slides that were extracted from the databases as well as from the reference lists of studies sourced through the search of the databases. The included papers were selected based on a number of eligibility criteria in order to meet the purpose of this review.

\subsection{Eligibility Criteria}

All included studies were required to meet the eligibility criteria of this review. The criteria included studies that only focused on Saudi healthcare organizations and which described EMR status and availability in Saudi Arabia. Studies which focused on EMR implantation barriers, facilitators and initiatives in Saudi Arabia were also eligible for inclusion. Studies included in this review had to be published between 2003 and 2013 and written in English. All included studies were prescreened for relevance based on the inclusion criteria. Any located studies that did not focus on Saudi Arabia or were not relevant to the area of EMR were not eligible for inclusion.

\subsection{Data Management}

The identified references from all searched databases were imported into bibliographic software (EndNote version X4.0.2). 


\section{RESULTS}

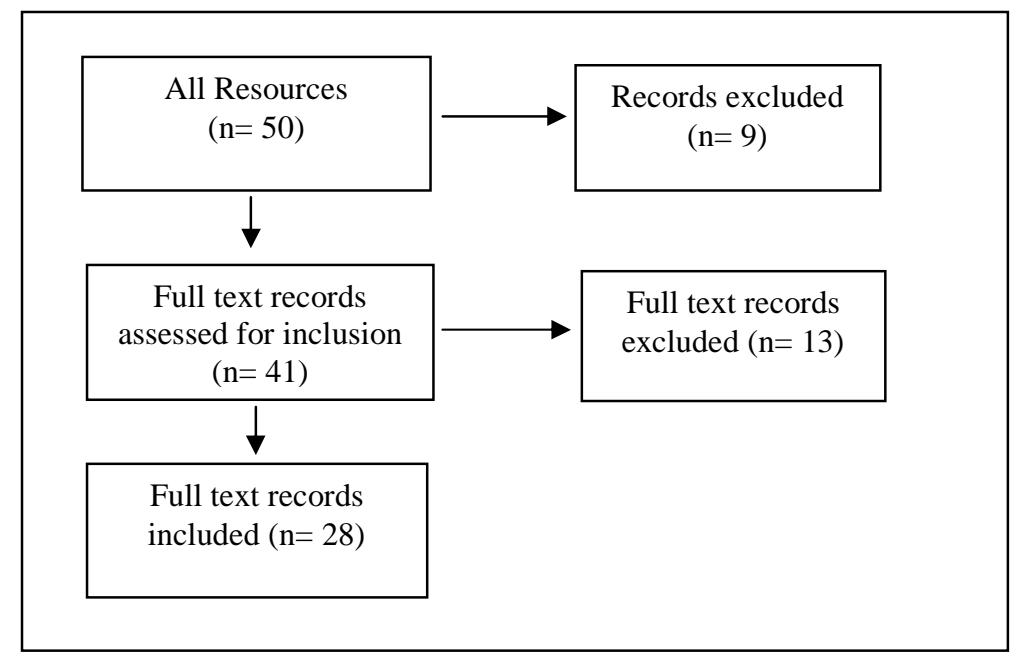

Figure 1. Flow diagram of systematic search strategy

\subsection{The Ministry of Health and other organizations Initiatives}

In 2008, Altuwaijri mentioned in an article that the Saudi MOH recently proposed an ambitious nation-wide implementation plan that would include all Saudi healthcare sectors (6) and enable the linking of both public and private healthcare organizations (16). At the beginning or early stage of implementation, the main issue needing to be accomplished was having a sufficient HIS to record and improve health related information, however, it was not necessarily computer based (4).

The Saudi Ministry of Health has spent millions of dollars developing and improving the healthcare system and services provided in Saudi Arabia, as well as implementing and improving HIS technologies (17). However, initiatives to implement HIS such as EMRs were all conducted independently by $\mathrm{MOH}$ and other governmental hospitals (6) Thus, it was and has been difficult to integrate patients' records, as patients have different records in different hospitals run by different governmental bodies (6). This situation occurs in most of the public and private hospitals in Saudi Arabia(6). Therefore, there is no standard EMR system used in the country (6). A complicating factor to nation-wide implementation appears to be the existence of a number of healthcare organizations that were under different governmental jurisdictions, such as the National Guard Health Affair (NGHA) and the Ministry of Defense and Aviation(17). It is noted that these institutions and several other hospitals have accomplished distinguished achievements in many fields including EMR implementation(17). However, because some of these non-MOH organizations set their own priorities and selected systems best aligned with their own needs, there was variation in the way EMRs were implemented (17). Such early variation in EMRs between governmental departments would lay the foundation for making attempts at uniform, national implementation problematic(17). The private sector similarly established its own systems, with little coordination with other sectors (4). While most of the extant literature focuses on $\mathrm{MOH}$ hospitals, there is some literature about hospitals in other sectors that also provide learning about EMR implementation in Saudi Arabia.

After several MOH hospitals initiated and implemented their own EMR system (6), in the year 2000, the Saudi government initiated a reform committee to review healthcare services (17). The 
reform committee highlighted a lack of a good HIS to manage patient records (17). Then, in 2002, an information technology strategic plan was developed based on the reform committee's recommendations, and it aimed to develop a national Electronic Medical Record system (18). In order for the plan and its aim to be accomplished, a number of steps were recommended by the reform committee (17). First and foremost, the committee recommended building a workforce specialized in health informatics, as skills in this areas were noted to be in scare supply (17). Other recommendations included the establishment of centers of excellence and professional associations in the field of health informatics (17). As a result of review's recommendations, the King Saud bin AbdulAziz University for Health Sciences (KAU-HS) at the National Guard, developed a two year Master program in health informatics, which commenced in 2005 (17). This program assisted in increasing the number of people in the workforce in this specialized field; by providing them with the requisite knowledge to practice in the field of health informatics in Saudi Arabia (17).

Apart of the Master's program, in 2005 the KAU-HS also developed the Saudi Association for Health Informatics (SAHI), as the reform committee recommended (17). One of the main objectives of the SAHI, was to conduct a conference every two years (19), focusing on e-health and health informatics issues in Saudi Arabia (20). The first conference was conducted in 2006 (10), and other conferences were held in 2008, 2010 and 2012 (21). The SAHI is the only recognized association in Saudi Arabia that focuses on the topic of Health Informatics and conducts events to discuss this topic and assist in the development of e-health in the country (18). The reform committee also recommended the need to establish a center of excellence for health informatics (21). Later in 2002, the KSAU-HS and the NGHA proposed the establishment of an electronic healthcare centre of research excellence (E-CoRE) (21). This centre would assist in the development and implementation of e-health applications and health information technology and its management in Saudi Arabia (21). The creation of the E-CoRE would also assist in achieving an improved healthcare delivery process as well as its quality and efficiency (21).

As a further initiative by the NGHA to expand the capability of the EMR system and the quality of services at King Abdulaziz Medical City's (KAMC) Ambulatory Care Center (ACC) of NGHA, a short messaging services (SMS) appointment reminder was implemented in 2008 (22). The SMS was integrated with the EMR system, which had a positive effect on improving the efficiency of it services by for example decreasing the rate of missed outpatient appointments (22). This initiative highlights the advantages of having EMRs, from which other Saudi hospitals may benefit. Another initiative to promote and develop HIS such as EMRs, is that the King Faisal Specialist Hospital and Research Centre (KFSH\&RC) in Riyadh established an e-health center in 1993 (23). E-health technologies include patient related electronic health records, telemedicine and several other information and communication health related technologies used in healthcare originations (24).

The MOH allocated 4 billion Saudi Riyals (around 1 billion US Dollar) during the years 2008 2011 to develop and implement e-health in Saudi Arabia (25). Additionally, in 2011 the MOH appointed an Information and Communication Technology (ICT) team and developed a 10 year ehealth strategic plan to improve the Saudi healthcare system and its services (18). A chronology, drawn from the literature, which summarizes major EMR initiatives in Saudi Arabia is outlined in Table 1. 
Health Informatics- An International Journal (HIIJ) Vol.3, No.2, May 2014

Table 1. EMRs in Saudi Arabia: A chronology of implementation milestones.

\begin{tabular}{|c|c|c|c|}
\hline Year & Sector & Action & Ref. \\
\hline 1988 & $\mathrm{MOH}$ & First introduction of EMR systems in Saudi Arabia. & (4) \\
\hline 1993 & KFSH\&RC & $\begin{array}{l}\text { First introduction of HIS and record health related information } \\
\text { electronically }\end{array}$ & (4) \\
\hline 1993 & $\mathrm{MOH}$ & $\begin{array}{l}\text { Telemedicine and Internet technology was introduced in Saudi } \\
\text { Arabia. }\end{array}$ & (4) \\
\hline 1993 & KFSH\&RC & Developed an e-health centre. & (23) \\
\hline 1999 & NGHA & $\begin{array}{l}\text { The first IT strategic plan for implementing HIS was developed } \\
\text { for the NGHA hospitals. }\end{array}$ & (42) \\
\hline 2000 & $\mathrm{MOH}$ & $\begin{array}{l}\text { A reform committee was formed to review the Saudi healthcare } \\
\text { services, and highlighted the lack of appropriate HIS. }\end{array}$ & (20) \\
\hline 2001 & $\mathrm{MOH}$ & $\begin{array}{l}\text { An information technology strategic plan was developed based on } \\
\text { the reform committee's recommendations. }\end{array}$ & (20) \\
\hline 2001 & NGHA & $\begin{array}{l}\text { The hospital purchased a commercial EMR system to be } \\
\text { implemented in all NGHA hospitals. }\end{array}$ & $(42)$ \\
\hline 2004 & NGHA & System was operational in Riyadh site. & (42) \\
\hline 2005 & $\begin{array}{l}\text { KAU-HS / } \\
\text { NGHA }\end{array}$ & $\begin{array}{l}\text { Commencement of a two year Master program in health } \\
\text { informatics. }\end{array}$ & (20) \\
\hline 2006 & $\begin{array}{l}\text { KAU-HS / } \\
\text { NGHA }\end{array}$ & $\begin{array}{l}\text { The Saudi Association for Health Informatics was developed and } \\
\text { its first conference was conducted. }\end{array}$ & (10) \\
\hline 2007 & $\begin{array}{l}\text { Ministry of } \\
\text { Defence \& } \\
\text { Aviation }\end{array}$ & $\begin{array}{l}\text { The north-western region of Tabuk Armed Forces hospital had its } \\
\text { first operational EMR system within all Armed Forces hospitals } \\
\text { in Saudi Arabia. }\end{array}$ & (43) \\
\hline 2008 & $\mathrm{MOH}$ & $\begin{array}{l}1 \text { billion US dollar was allocated for e-health development and } \\
\text { implementation in Saudi Arabia. }\end{array}$ & (25) \\
\hline $\begin{array}{l}2008 \\
- \\
2010\end{array}$ & NGHA & $\begin{array}{l}\text { In } 2008 \text {, the NGHA started to implement EMR system in other } \\
\text { sites, and was fully implemented and became operational in all } \\
\text { four NGHA sites in } 2010 \text {. }\end{array}$ & (42) \\
\hline 2010 & NGHA & $\begin{array}{l}\text { the Arab Health Conference awarded the NGHA the Middle East } \\
\text { Excellence Award in electronic health records }\end{array}$ & (42) \\
\hline 2011 & $\mathrm{MOH}$ & $\begin{array}{l}\text { An Information and Communication Technology (ICT) team was } \\
\text { assigned to develop a } 10 \text { year e-health strategic plan to improve } \\
\text { the Saudi healthcare system and its services. }\end{array}$ & (18) \\
\hline 2011 & $\mathrm{MOH}$ & $\begin{array}{l}\text { The percentage level of EMR system implementation in } 19 \mathrm{MOH} \\
\text { hospitals, in the Eastern province of Saudi Arabia was identified } \\
\text { to be } 15.8 \%\end{array}$ & (29) \\
\hline 2012 & $\mathrm{MOH}$ & $\begin{array}{l}\text { The level of EMR system implementation in } 22 \mathrm{MOH} \text { public } \\
\text { hospitals was: } \\
11 \text { hospitals had fully implemented EMR system. } \\
8 \text { hospitals had EMR implementations were in progress. }\end{array}$ & (28) \\
\hline
\end{tabular}

\subsection{The available EMR systems in Saudi Arabia}

The literature reveals that the Saudi $\mathrm{MOH}$ was interested in and conducted several initiatives in the field of HIS and wanted to implement EMR nationally (4). This interest in EMRs commenced due to a number of reasons. The MOH wanted to keep up with all the technological developments in the field of health, especially in relation to patient records (14). However, the literature 
indicates that until 2012, most of the MOH hospitals have had paper-based patients recording systems (5). There has been a dramatic increase in the amount of health information, because of the rapid growth in Saudi population (14). Despite the increased interest and investment by the $\mathrm{MOH}$ in HIS, its uptake has been very low (6) and most of the available systems are basic (4). Basic systems tend to focus on the administrative aspects such as admission and discharge dates rather than being patient-centered (14), such as patient selection by ensuring that services are offered to the right patient, ordering medications and providing notifications about allergies (26). Although the literature does not provide information on the exact number of hospitals in Saudi hospitals that have an EMR system, it is agreed that very few hospitals are in an advanced stage of HIS implementation (6).

In 2006, Alanzay conducted a research study of EHR implementation in six major hospitals in Riyadh administered by different governmental bodies (11). Alanzy's research noted that EMR systems availability varied from one hospital to another in Saudi Arabia (11). Additionally, participants in Alanazy's research had differing perceptions of the level and extent of the use of EMRs in the hospitals in which they worked (11). These findings highlight that some of the healthcare providers in Saudi hospitals are unaware of the functions that are available within the hospital's HIS system. The findings may also imply that some of the hospitals are still using the paper-based records system in some of their departments. These finding are in keeping with several other studies (5), which indicate a lack of staff awareness in some hospitals about the functions of the implemented HIS and is one of the barriers that may be affecting the low and slow adoption of EMRs (3). Therefore, hospital management needs to understand end-users perceptions, needs and computer literacy levels for using the implemented EMR (27). Hospital mangers also need to ensure that the current and potential users of the EMR system are aware of the available functions and customization based on a role-specific approach (27). Another study surveyed $22 \mathrm{MOH}$ public hospitals in Riyadh city for EMRs availability (28). The study found that there was a low number of EHRs implementation within these 22 hospitals (28). This finding also confirms the low and slow uptake of EMRs in Saudi hospitals (6).

Another study in 2011 (29), explored the level of EMR system implementation in $19 \mathrm{MOH}$ hospitals, in the Eastern province of Saudi Arabia (29). The study found that only three out of the 19 hospitals $(15.8 \%)$ had an EMR system, while the remaining 16 did not have an EMR system (18). The study noted the low percentage (15.8\%) of EMR uptake among the surveyed hospitals. It appears that the three hospitals that had implemented EMR were using the same EMR software and had the same functionalities (29). The study suggested that the low uptake of EMRs might be associated with a lack of interhospital coordination, collaboration and planning (29). Another reason mentioned in the study for the lack of uptake in some hospitals, was related to the workload of physicians (29). It was thought that busy physicians may have insufficient time to use the system (29).

Security concerns were another issue that the study proposed as a reason for limited uptake of EMR in the 16 out of 19 hospitals (29), which had not implemented EMRs (29). This confirms other research in the literature which suggests the importance of data security (30), as well as the central role of a well-structured and coordinated implementation plan to aid successful EMR implementation (31). From reviewing the literature, it is clear that up until 2012, EMR uptake and implementation in Saudi hospitals was low and that several issues were obstructing the uptake (6). However, interest in the field of EMRs is increasing in Saudi Arabia, with one study being undertaken in 2003 and eight studies in 2012, as shown in (Figure 2). Having described the uptake of EMRs in Saudi Arabia, the study now turns to identify the factors that have assisted or hindered EMR implementation in Saudi hospitals (32). 


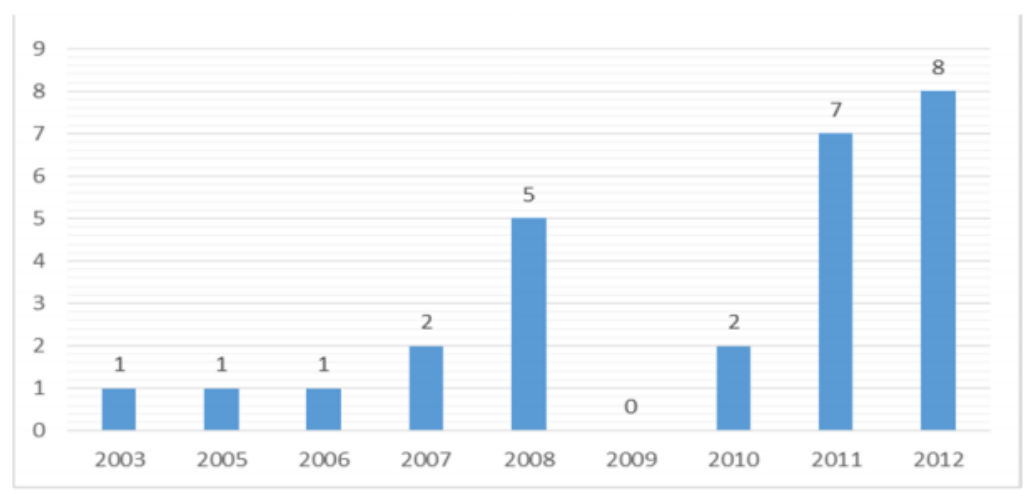

Figure 2. Number of EMR related studies in Saudi Arabia

\subsection{Successful EMR system implementations in Saudi Arabia.}

The literature does not reveal the level of EMR system uptake at a national level in Saudi Arabia (18). So it is uncertain how many MOH hospitals have an EMR system and/or the level of such system uptake (18). The literature provides a number of studies in different hospitals in different cities focusing on EMRs implementation and issue related to their implementation. There are very good examples in the literature of a successful implementation of EMR system in some of the major Saudi hospitals (18). This section provides a summary of some of these examples.

\subsubsection{The NGHA Experience for a Successful EMR Implementation}

The NHGA has four hospitals and 60 primary and secondary healthcare centers in different regions of Saudi Arabia (14). The four hospitals are located in four different cities; Riyadh, Jeddah, Dammam and Ahsa (28). The NGHA health organizations have 2000 in-patients beds and serve 2.5 million out-patients and 60,000 in-patients annually (33). All four NGHA hospitals have EMR systems that are integrated with each other (18), meaning that all four hospitals are linked and share an EMR system (18). The NGHA started to consider EMR implementation as far back as early the 1990s (14), and thus was a leader in this type of initiative in Saudi Arabia (14). In 1999, the NGHA developed its first IT strategic plan for implementing EMR (14). The NGHA IT strategic plan consisted of two main phases for EMR implementation and development (14). The first phase was the "IT visioning phase" run by an IT steering committee (14). Phase one aimed to establish an informatics department and information system (14). Additionally, phase one was responsible for ensuring that both the "IT visioning phase" and the proposed IT project were coordinated (14). Phase one focused on all the deployment, evaluation and improvement aspects of the EMR which were to follow.

The second phase of the NGHA IT strategic plan was the "achieving of the IT vision" phase (14). In order for the NGHA to fulfill this second phase, it developed an Information System and Informatics Department (ISID) (14). Since the NGHA had an IT department prior to the IT strategic plan, there was a need to link both the previous IT department with the new IT strategic plan (14). The NGHA specifically recruited a number of staff and provided them with training in Health Informatics in order to manage this linkage (14). Later, in 2001, the NGHA purchased an EMR system for all NGHA sites (14). From then the NGHA implemented the system in Riyadh site (14). In 2004, the system was fully implemented and was operational in only the Riyadh site (14). In 2010, the system was implemented and operational in all NGHA sites as well (14). Furthermore, the EMR system at the NGHA served more than 15,000 users in 2010 (14). After completing this phase, the lessons learnt from this experience were documented (14). The main 
lesson learned was that an IT strategic plan was a crucial aspect for successful EMR system implementation (14). Furthermore, there were potential risks that the organization needed to be aware of and mitigate (14). Then, the outcomes, benefits and lessons learned from all pervious activities were recorded and submitted to the "IT visioning phase", to ensure that the goals of the strategic plan were accomplished (14). The study also mentioned that the availability of an IT department and its role as well as the role of qualified staff and saw these factors as key lessons for successful implementation (14). Other lessons learned included sufficient and appropriate training for users, system integration and the availability of a strong project manager (14). Having a defined and well-structured plan for implementing EMR system in the NGHA hospitals has also been attributed to assisting successful implementation (14). In fact the EMR implementation in NGHA hospitals has been noted as one of the best examples of EMR implementation in Saudi Arabia and possibly in other surrounding Arab countries (14). In 2010, the Arab Health Conference awarded the NGHA the Middle East excellence award in electronic health records(34). This award was the first award to be received by a Saudi health organization (14).

Furthermore, the NGHA implemented an additional feature for the EMR system (33). The NGHA implemented a computerized physician order entry (CPOE), which was integrated with the available EMR system (33). CPOE is a system that improves the workflow by notifying the users of any alerts or errors, such as when there is a duplicate order for a treatment (33). The COPE system has several other features, and all data entered in the system are linked with the EMR system (33). Addressing potential user resistance and providing training sessions were aspects that the NGHA considered as important when adopting this new system (33). Another study in Saudi Arabia also emphasized the importance of the availability of training sessions in order to increase users' satisfaction (24).

After reviewing the NGHA experience in implementing EMR system in all NGHA sites, it is clear that EMR implementation is an achievable task in Saudi Arabia. It is however, acknowledged that implementation in four tertiary NGHA hospitals may be less complex than implementation across $244 \mathrm{MOH}$ hospitals. Nonetheless, the NGHA experience appears to provide lessons for other health providers seeking to implement EHRs. Clearly EMR implementation is assisted by appropriate planning, resources, skills and management. Although EMR uptake is low in Saudi, other hospitals can benefit from the NGHA experience, as all NGHA sites are in Saudi and thus share some cultural and contextual commonality with other Saudi hospitals.

\subsubsection{The Armed Forces hospitals Experience for a Successful EMR Implementation}

There are five Armed Forces hospitals under the Saudi Ministry of Defense and Aviation (11) and all five hospitals have a fully implemented and integrated EMR system (35). In 2007, the first system was implemented and was operational in the north-western region of Tabuk Armed Forces hospital (35). The EMR system of the Armed Forces hospitals was considered to be the largest EMR system operating in Saudi Arabia (35). Once again implementation of EHRs in the Armed Forces hospitals may be less complex due to the smaller number of hospitals, compared to the $\mathrm{MOH}$. Additionally, a military culture with a clear chain of command and decision making may have assisted the implementation of a fully integrated EMR.

\subsubsection{King Faisal Specialist Hospital and Research Center Experience for a Successful EMR Implementation}

The King Faisal Specialist Hospital and Research Centre (KFSH \& RC) is noted as a leading healthcare provider in Saudi Arabia (4). It first introduced telemedicine and health HIS in 1993 
(4). The KFSH \& RC hospital in Riyadh has almost fully implemented an EMR system (11), and is reported to have the latest IT (6).

Having reviewed the literature about EMR implementation in Saudi Arabia, the review now turns to discuss the identified barriers.

\section{BARRIERS TO EMR IMPLEMENTATION IN SAUDI ARABIA}

In 2006, a number of barriers were found to be obstructing the adoption of EMRs in Saudi hospitals (11). Examples of these barriers include cost, privacy concerns, complexity of software as well as a lack of uniform standards and vendor support and maintenance (11). However, the main barrier found in the workplace was "Lack of knowledge and experience to use computers amongst health personnel" (36). This barrier was noted as $15 \%$ higher in public hospitals than private hospitals (36). Another study in 2012 (37) also referred to computer literacy as one of the barriers considered to be obstructing EMRs implementation in Saudi Arabia (37). The computer literacy barrier has also been found to hinder EMRs implementation in other countries outside of Saudi Arabia (11). In 2010, another study was conducted to examine the current barriers of EMRs implementation in two private and three public MOH hospitals in Jeddah (36). Three key barriers to successful implementation of EMRs in Saudi Arabia have been identified from the literature. These barriers are social barriers, technical barriers and resource barriers (36). Each of these barriers will be considered in turn.

\subsection{Social Barriers}

A number of social barriers have been identified by various authors, with the main social barriers being lack of computer literacy and resistance to use of new system (36). Another identified barrier to EMR implementation in Saudi Arabia is the language issue, since Arabic is the first language and yet the systems which are implemented are in English (36). Although these barriers had not previously been identified in Saudi Arabia, they are in keeping with findings in the broader international literature. Both Alanazy's and Hasanain's research shows that implementation barriers were apparent despite the two studies occurring in different time periods as well as in different geographical arrears (central region in 2006 and western region in 2010, respectively). Thus time alone will not solve or overcome barriers to EMR implementation (3), and effective measures are needed to facilitate the implementation of such systems.

As previously mentioned physician concern with workloads when using EMRs in Saudi hospitals, was reported to be a barrier for EMRs implementation (29). A study by Aldosari (2003) in Saudi Arabia, examined physicians' attitudes towards EMRS (1). The study found that the attitudes of physicians are affected by several factors (1). Some of these factors were healthcare organizations' support, ease of using the system and the potential benefits of using EMRs (1). Another study by Mohamed and El-Naif in 2005, assessed physician, nurse and patient views of EMRs and physicians' views for using EMR systems in the Military hospital in Riyadh (38). It was noted that $90 \%$ of the physicians were concerned that using such a system would mean that they would have to enter the data into the system (38).Their main concern was that reviewing results electronically and entering data would take more time than traditional paper-based methods (38). Also, the majority of the physicians were worried that the system would decrease their productivity and cause them see fewer patients (38). Physicians with low computer literacy had more concerns with perceived workload issues stemming from EMR usage (38). It was recommended in Mohamed and El-Naif's study that there is a need to engage physicians and practitioners in computer activities and training in order to successfully implement EHRs (38). It was also recommended that strong support needs to be provided by the $\mathrm{MOH}$ for all stages of 
implementing EMRs (38). As well as identifying barriers, Hasanain's (2010) study also suggested a number of solutions to address EMR implementation barriers. The preferred solution by the study participants for the "Lack of knowledge and experience to use computers amongst health personnel" barrier was educating and training the staff in how to use the new system. Such a solution can be accomplished by undertaking a needs assessment protocol followed by a tailored training program or courses based on the results of that assessment (36).

\subsection{Technical Barriers}

Examples of technical barriers that were identified in previous research were instability of EMR vendors, lack of system standardized systems and complexity of the implemented EMR system (36). In 2011, a study referred to other EMR technical barriers that needed to be addressed, in order to have a national and integrated system in Saudi Arabia. These barriers were integration issues due to the diversity of the implemented HIS (37), security concerns with using the system (39), and lack of having a universal patient identifier (40). These barriers are considered to be serious hindrances to any EMR implementation plan. Lack of standard EMR systems in Saudi hospitals is an additional barriers hindering the implementation of a national EMR system (41).

EMR system implementation should ideally have regular evaluation during each stage of implementation (28). Such evaluations would lead EMR implementation to be more feasible as lessons could be learned from previous experiences (28). This barrier of a lack of a standard for EMR implementation exists due to the absence of a national regulator. (10). Regular evaluation, a national regulator and using a standardized system are core features for an integrated EMR system (10), as should be incorporated into any future EMR implementation in Saudi Arabia (18).

\subsection{Resources Barriers}

Hasanain (2010) identified a number of additional barriers (36) which related to resources. These additional barriers include a lack of human resources, lack of computers for staff and a lack of other technological recourses such as printers and even ink.

All in all, the identified EMR barriers in Saudi hospitals appear to be obstructing EMR adoption (16) . Some of these barriers were identified in 2006, and confirmed in a study in 2010.

\section{DisCUSSION AND CONCLUSION}

Overall, the exact level of EMR implementation nationally in Saudi Arabia could not be determined from the literature. Studies of $\mathrm{MOH}$ hospitals tended to be conducted in particular towns or regions and from this information, it would appear that implementation has been slow and low. The roll-out of EMRs in NGHA, military and private hospitals appears to be more advanced and may have been assisted by factors such as culture and autonomy in decision making and the smaller size of the organizations compared with MOH hospitals.

The literature reveals that the low uptake of EMR implementation in $\mathrm{MOH}$ hospitals is due to a number of technical, social and resource barriers. It is noted that the MOH has undertaken a number of initiatives and actions to implement and improve EMRs in its hospitals. Initiatives are still underway and plans for a national integrated EMR system is one of the main priorities of the Saudi MOH. Clearly coordinated and coherent initiatives are needed to assist integrated EMR implementation in Saudi Arabia. 
The current study had a number of limitations. The studies for inclusion spanned only a decade and articles in the field grew in number toward the end of the decade. It is possible that more facilitators and barriers may have been identified, if the time period had been longer. There were however, no studies in the field, in Saudi Arabia in the years prior to 2003. Only articles written in English were included in the study, which may have limited the findings. Finally, the literature focused on EMR implementation is Saudi Arabia, and thus the extent to which the findings can be extrapolated to other jurisdictions is limited.

Despite the limitations of the current study this article is the first to systematically review the progress of and challenges to EMR implementation in Saudi Arabia. It is also the first study which has developed a chronology of EMR implementation milestones from the extant literature. Improving the awareness of the challenges to successful implementation and documenting the progress to date, may assist Saudi hospitals as they plan for a national integrated EMR system.

\section{REFERENCES}

[1] Cesnik B, Kidd MR. History of health informatics: a global perspective. Studies in health technology and informatics. [Historical Article]. 2010;151:3-8.

[2] Al Jarullah A, El-Masri S. Proposal of an architecture for the national integration of Electronic Health Records: a semi-centralized approach. Stud Health Technol Inform. 2012;180.

[3] Granlien MF, Hertzum M, Gudmundsen J. The gap between actual and mandated use of an electronic medication record three years after deployment. Studies in health technology and informatics. 2008;136:419-24.

[4] Alsahafi Y. STUDIES OF EHR IMPLEMENTATION AND OPERATION IN DIFFERENT COUNTRIES WITH PARTICULAR REFERENCE TO SAUDI ARABIA: Massey University; 2012.

[5] Aldajani M. Electronic Patient Record Security Policy in Saudi Arabia National Health Services: De Montfort University 2012.

[6] ALTUWAIJRI M. Electronic-health in Saudi Arabia. Just around the corner? Saudi Med J. 2008;29(2):171-8.

[7] Davidson P. Health Information System: Auerbach Publications, New York; 2000.

[8] McLean V. Electronic Health Records Overview. National Institutes of Health National Center for Research Resources, Citeseer. 2006.

[9] ISO/TC. Electronic Health Record Definition, Scope, and Context. ISO/TC 215 Technical Report; 2003 [28/2/2010]; Available from: http://secure.cihi.ca/cihiweb/en/downloads/infostand_ihisd_isowg1_mtg_denoct_contextdraft.pdf.

[10] Alkraiji A, Jackson T, Murray I. Barriers to the widespread adoption of health data standards: an exploratory qualitative study in tertiary healthcare organizations in saudi arabia. J Med Syst. 2013 Apr;37(2):9895.

[11] Alanazy S. Factors associated with implementation of electronic health records in Saudi Arabia: D., UNIVERSITY OF MEDICINE AND DENTISTRY OF NEW JERSEY, New Jersey, USA.; 2006.

[12] MOH. A Review of Health Situation, Ministry Of Health,. 2006 [19/3/2010]; Available from: http://www.moh.gov.sa/statistics/stats2007/Book Seha02.pdf.

[13] Khudair AA. Electronic health records: Saudi physicians' perspective. 5th IET International Seminar on Appropriate Healthcare Technologies for Developing Countries (AHT 2008)2008. p. 7-.

[14] ALTUWAIJRI M. Health Information Technology Strategic Planning Alignment in Saudi Hospitals: A Historical Perspective. Journal of Health Informatics in Developing Countries 2011;5(2).

[15] WHO/CCS. Cooperation Strategy for WHO and Saudi Arabia 2006-2011, World Health Organization. $2006 \quad$ [19/4/2010]; Available from: http://www.who.int/countryfocus/cooperation_strategy/ccs_sau_en.pdf.

[16] Khalifa M. Barriers to Health Information Systems and Electronic Medical Records Implementation. A Field Study of Saudi Arabian Hospitals. Procedia Computer Science. 2013;21:335-42.

[17] Altuwaijri M. Supporting the Saudi e-health initiative: the Master of Health Informatics programme at KSAU-HS. EMHJ. 2010;16(1). 
Health Informatics- An International Journal (HIIJ) Vol.3, No.2, May 2014

['8] Albishi H. Health Information Management in the Kingdom of Saudi Arabia. 2011 [10/11/2013]; Saudi Association for Health Informatics]. Available from: http://www.sahi.org.sa/article_details.php?article_id=9.

[19] SAHI. The Saudi Association for Health Informatics (SAHI). 2014 [23/01/2014]; Available from: http://www.imia-medinfo.org/new2/node/108.

[20] Altwaijir M, Aldosari B. Health Informatics Master Program at King Saud bin Abdulaziz University for Health Sciences, Riyadh, Saudi Arabia. Yearb Med Inform. 2008;145(9).

[21] Househ M, ALTUWAIJRI M, Aldosari B. Establishing an Electronic Health Center of Research Excellence (E-CoRE) within the Kingdom of Saudi Arabia. Journal of Health Informatics in Developing Countries. 2010;4(1).

[22] Altuwaijri MM, Sughayr AM, Hassan MA, Alazwari FM. The effect of integrating short messaging services` reminders with electronic medical records on non-attendance rates. Saudi medical journal. 2012 Feb;33(2):193-6.

[23] El-Mahalli AA, El-Khafif SH, Al-Qahtani MF. Successes and challenges in the implementation and application of telemedicine in the eastern province of Saudi Arabia. Perspect Health Inf Manag. [Research Support, Non-U.S. Gov't]. 2012;9:1-27.

[24] Nour El Din MM. Physicians' use of and attitudes toward electronic medical record system implemented at a teaching hospital in saudi arabia. J Egypt Public Health Assoc. 2007;82(5-6):34764.

[25] Almalki M, Fitzgerald G, Clark M. Health care system in Saudi Arabia: an overview. East Mediterr Health J. [Research Support, Non-U.S. Gov't Review]. 2011 Oct;17(10):784-93.

[26] Middleton B, Bloomrosen M, Dente MA, Hashmat B, Koppel R, Overhage JM, et al. Enhancing patient safety and quality of care by improving the usability of electronic health record systems: recommendations from AMIA. J Am Med Inform Assoc. [Guideline]. 2013 Jun;20(e1):e2-8.

[27] Unertl KM, Johnson KB, Lorenzi NM. Health information exchange technology on the front lines of healthcare: workflow factors and patterns of use. J Am Med Inform Assoc. [Multicenter Study, Research Support, N.I.H., Extramural,Research Support, Non-U.S. Gov't, Research Support, U.S. Gov't, P.H.S.]. 2012 May-Jun;19(3):392-400.

[28] Aldosari B. An Evaluation of EHR System Audit Functions in a Saudi Arabian Hospital. Journal of Health Informatics in Developing Countries. 2012;6(2).

[29] Bah S, Alharthi H, El Mahalli AA, Jabali A, Al-Qahtani M, Al-kahtani N. Annual survey on the level and extent of usage of electronic health records in government-related hospitals in Eastern Province, Saudi Arabia. Perspect Health Inf Manag. 2011;8:1b.

[30] Almulhem A. Threat modeling for electronic health record systems. J Med Syst. 2012 Oct;36(5):2921-6.

[31] Deutsch E, Duftschmid G, Dorda W. Critical areas of national electronic health record programs--Is our focus correct? International Journal of Medical Informatics. [doi: DOI: 10.1016/j.ijmedinf.2009.12.002]. 2010;79(3):211-22.

[32] Aanestada M, Jensen T. Building nation-wide information infrastructures in healthcare through modular implementation strategies. The Journal of Strategic Information System. 2011.

[33] Altuwaijri MM, Bahanshal A, Almehaid M. Implementation of computerized physician order entry in National Guard Hospitals: assessment of critical success factors. J Family Community Med. 2011 Sep;18(3):143-51.

[34] Altuwaijri MM. Achieving excellence in Electronic Health Record deployment in Middle East hospitals. Biomedical Engineering and Informatics (BMEI). 2011;4:1919 - 23

[35] Largest electronic health system in Saudi Arabia up and running. Saudi Gazette. 2008.

[36] Hasanain R. Strategies and Solutions to Overcome Technical and Social Barriers When Implementing Electronic Health Records in Public and Private Hospitals in Saudi Arabia. [Master of Health Service Management with Honours]. In press 2010.

[37] Al kheliwi S. Adoption Electronic Medical Record And Cultural Effect. London: Brunel University; 2012.

[38] Mohamed BA, El-Naif M. Physicians', nurses' and patients' perception with hospital medical records at a military hospital in riyadh, saudi arabia. J Family Community Med. 2005 Jan;12(1):49-53.

[39] Alnuem M, El-Masri S, Youssef A, Emam A. . Towards Integrating National Electronic Care Records in Saudi Arabia. 12th Int'l Conference on Bioinformatics and Computational Biology (BIOCOMP'11); Las Vages, Nevada, USA2011. p. 777-82. 
[40] Emam A, Youssef A, Elmasri S, Alnuem M. Integrating Electronic Health Records Using Universal Patient Identifiers KSA. Dept of Information Systems. 20112011.

[41] Alkraiji A, Jackson T, Murray I. Health data standards and adoption process: Preliminary findings of a qualitative study in Saudi Arabia. Campus-Wide Information Systems. 2011;28(5):345-59.

[42] ALTUWAIJRI M. Health Information Technology Strategic Planning Alignment in Saudi Hospitals: A Historical Perspective. Journal of Health Informatics in Developing Countries. 2011; Vol. 5 (No. 2).

[43] Menon V. Saudi Armed Forces adopts e-health system. Arabian Business. 2008.

\section{Author(s)}

Rihab Hasanain is a PhD candidate in Health Services Management, School of Public Health and Social Work at Queensland University of Technology. Her topic of research is focusing on EMRs implementation in public hospitals in Saudi Arabia.

Dr. Kirsten Vallmuur is the associate supervisor. She is the Senior Research Fellow with the Centre for Accident Research and Road Safety - Queensland. She has expertise in the analysis and understanding of large morbidity and mortality coded data sets, injury surveillance systems, trauma data linkage, health classifications and injury classifications. She is a member of the World Health Organisation ICD-11 Revision Topic Advisory Group for Injury and External causes, and is the chair of the research committee for the Australasian Mortality Data Interest Group.

Professor Michele Clark is an allied health professional and has worked as a both a clinician and senior researcher. Prof Clark is a former recipient of a NHMRC Post-doctoral fellowship and has an extensive research background in prehospital and emergency care utilization patterns, aged care and policy implementation. She was the Inaugural Director of the Australian Centre for Prehospital Research, which was a collaborative centre of the Qld Ambulance Service and the University of Queensland. Career highlights include working at the United Nations in New York for International Year of Older Persons and being a former Assistant Commissioner (Allied Health) on the Health Quality and Complaints Commission. 